\title{
O plano de carreira do magistério em Porto Alegre: reflexões à luz do ordenamento jurídico nacional pós 1988
}

\author{
Juca Gil ${ }^{1}$ \\ jucagil@uol.com.br \\ Franciele Nepomuceno Netto ${ }^{2}$ \\ shellynepo@hotmail.com \\ Isabel Letícia Pedroso de Medeiros ${ }^{3}$ \\ isabellpm@yahoo.com.br
}

Resumo

$\mathrm{O}$ presente artigo pretende contribuir para a reflexão acerca dos movimentos e impasses inerentes à construção de direitos trabalhistas dos docentes brasileiros através da análise do processo que definiu os conteúdos e as práticas do Plano de Carreira do Magistério em Porto Alegre, no Rio Grande do Sul. Buscou-se aqui, principalmente, compreender os detalhes da legislação municipal concernente às atividades dos professores, a qual inclui peculiaridades como um adicional de $50 \%$ na remuneração dos profissionais que atuam na educação especial ou ainda a redução do número de horas/aula semanais em função da idade e do tempo de docência. Constatou-se que a obtenção, manutenção e execução das condições de trabalho em vigor, no caso analisado, tiveram forte influência

\footnotetext{
1 Doutor em Educação pela Universidade do Estado de São Paulo, Brasil (2007). Professora da Faculdade de Educação da Universidade Federal do Rio Grande do Sul.

2 Pedagoga pela Universidade Federal do Rio Grande do Sul , Brasil (2010). Professora da Prefeitura Municipal de São Leopoldo.

3 Doutora em Educação pela Universidade Federal do Rio Grande do Sul, Brasil (2009). Professora da Prefeitura Municipal de Porto Alegre.
} 
da intervenção realizada pela organização sindical.

Palavras chave: plano de carreira docente, direitos trabalhistas, educação municipal.

A educação no Brasil se constituiu desde seus primórdios em trajetória caracterizada pela fragilidade ou inexistência de políticas públicas, descompromisso do estado, elitização e privatização, escassez de oferta, parcos recursos e processos tardios, se comparados a outros países, inclusive da América Latina. Em consonância com esse contexto, a atividade docente, não obstante os avanços no campo legal, careceu de estruturação da carreira, formação qualificada, reconhecimento, valorização e salários dignos (CAMARGO \& JACOMINI, 2011).

A Constituição Federal de 1988 (CF/88) foi um marco histórico na busca da inversão dessa trajetória e da garantia do direito à educação, fundada nos princípios da universalidade, equidade e qualidade, o que também se refletiu na valorização da profissão docente, a qual foi alçada ao patamar de um dos princípios do ensino no país, constante do Artigo 206, inciso V, o qual afirma a valorização dos profissionais do ensino, através de planos de carreira e de piso salarial profissional (BRASIL, 1988). A legislação específica para a educação, decorrente da Constituição, qual seja, a Lei n. 9.394/96 (Lei de Diretrizes e Bases da Educação Nacional - LDB) e a Lei n. 10.172/01 (Plano Nacional de Educação - PNE), dedicam um capítulo/título específico que afirmam o princípio constitucional, caracterizam o profissional da educação e desdobram condições para a constituição e desempenho da carreira.

A LDB, no Título VI, Artigo 67, reafirma o princípio constitucional e traz elementos da valorização dos profissionais da educação, detalhando o expresso na CF/88, dentre os quais: ingresso por concurso, tempo remunerado para formação, estudos e planejamento, piso salarial, progressão funcional e condições de trabalho (BRASIL, 1996).

O PNE, por sua vez, afirma no Capítulo IV que a melhoria da qualidade do ensino "somente poderá ser alcançada se for promovida, ao mesmo tempo, a valorização do magistério", a qual deve ser obtida por meio de uma política global, que inclua formação profissional inicial, condições de trabalho, salário e carreira e formação continuada (BRASIL, 
2001). Além disso, aponta, como requisito da valorização, "salário digno e competitivo no mercado de trabalho" e "compromisso social e político do magistério", esse último demandando a previsão de avaliação do desempenho. Dentre os objetivos e metas, destacamos, ainda, as questões relativas ao período reservado para planejamento: "destinar entre vinte e vinte e cinco por cento da carga horária dos professores para a preparação das aulas, avaliações e reuniões pedagógicas". (BRASIL, 2001)

Outra iniciativa nacional foi o Plano de Metas Compromisso Todos pela Educação, criado através do Decreto n. 6.094/07 no âmbito do Plano de Desenvolvimento da Educação (PDE), no qual se encontram sete metas que visam à regulação dos profissionais da educação, instituindo e implementando: formação inicial e continuada, plano de carreira, valorização do mérito e avaliação do desempenho, efetivação do período probatório, participação de professores e funcionários na elaboração do projeto pedagógico, coordenadores pedagógicos nas escolas, definição de regras para nomeação e exoneração de diretores (BRASIL, 2007a).

Legislações posteriores reforçam a valorização e a remuneração dos profissionais da educação como constituintes das políticas educacionais que visam ao desenvolvimento e à qualidade da educação. A Lei n. 11.494/07, que institui o Fundo de Manutenção e Desenvolvimento da Educação Básica e de Valorização dos Profissionais da Educação (Fundeb), afirma, em seu Artigo 20: “Os Fundos destinam-se à manutenção e ao desenvolvimento da educação básica pública e à valorização dos trabalhadores em educação, incluindo sua condigna remuneração"4 (BRASIL, 2007b)

Por sua vez, a Lei n. 11.738/08 institui o piso salarial para a educação básica para os professores com formação de nível médio, com carga horária de trabalho de quarenta horas semanais, cujos valores monetários devem sofrer atualização anual, no mês de janeiro, de acordo com critérios estabelecidos, no Artigo 5 , dessa mesma lei (BRASIL, 2008). Também aponta que as atividades de interação com os educandos não devem exceder a dois terços (2/3) da jornada, destinando, em decorrência, um terço $(1 / 3)$ para as outras atividades relacionadas ao trabalho docente,

4 A legislação do Fundef (Lei $\left.n^{\circ} 9.424 / 96\right)$, em seus artigos $9^{\circ}$ e 10 , é direta quanto à carreira e à remuneração docentes. 
tais como planejamento, formação, estudos, etc. (BRASIL, 2008).

A Resolução n. 2, de 28 de maio de 2009, do Conselho Nacional de Educação (CNE) fixa as diretrizes para os Planos de Carreira e Remuneração dos Profissionais do Magistério da Educação Básica Pública, ratificando aspectos da carreira docente, tais como acesso, formação do professor, jornada de trabalho e formação continuada, progressão na carreira e avaliação de desempenho, já abordados nas legislações citadas (BRASIL, 2009).

Cabe salientar um fundamento em todas as disputas em torno da democratização e da qualidade da educação, que certamente enquadra também o debate sobre a valorização docente: a gestão democrática. Estabelecida como princípio na CF/88 (Art. 206, inciso VI) e na LDB (Art. $3^{\circ}$, inciso VIII), possui decorrências em todas as demais legislações, já que permite protagonismo aos segmentos da comunidade escolar, e dentre esses os professores, na elaboração das políticas educacionais, no controle social e na definição do conceito de qualidade.

A partir desse recorrido na legislação atual, percebe-se o reconhecimento do profissional docente, no novo ordenamento, como elemento diferencial nas políticas educacionais, considerando sua formação inicial, formação continuada, condições de trabalho, carreira e salário como aspectos a serem regulados em favor da qualidade da educação.

Esses mesmos aspectos foram ratificados nas discussões da Conferência Nacional de Educação (CONAE), cujo documento base dedicou um capítulo para o tema: Eixo IV - Formação e Valorização dos Profissionais da Educação. Em seu segundo parágrafo, há a seguinte referência:

Mas, possivelmente, em nenhum outro momento histórico tenham merecido tamanha ênfase, por parte de diferentes agentes públicos e privados, instituições, organismos nacionais, internacionais e multilaterais, como nas últimas décadas, reconhecendo o protagonismo dos/das profissionais da educação no sistema educacional. (BRASIL, 2010a, p. 77).

Findada a década de vigência do PNE 2001, o Projeto de Lei n. $8.035 / 10$, que objetiva instituir novo plano para o próximo decênio, 
também enfatiza os profissionais da educação, destinando quatro de suas vinte metas para o tema da formação e valorização docentes: garantir a todos os docentes da educação básica formação em nível superior, formar pelo menos metade dos profissionais em nível de pósgraduação, aproximar o rendimento médio dos integrantes do magistério ao rendimento médio de outras carreiras com escolaridade equivalente, assegurar, no prazo de dois anos, planos de carreira para os docentes em todos os sistemas de ensino (BRASIL, 2010b).

Assim, tanto a legislação vigente quanto os debates para a projeção de um cenário para a próxima década elencam como fundamental o papel exercido pelos trabalhadores em educação, buscando superar a histórica desvalorização da profissão, os baixos salários, a desigualdade salarial em relação a carreiras de mesma exigência acadêmica, a intensificação da carga horária de trabalho, a dupla jornada, enfim, todos os componentes que concorreram para a precarização do trabalho docente, ainda que possamos perceber ambiguidades e contradições, pois a legislação incorpora disputas de paradigmas democráticos numa perspectiva popular e participativa com paradigmas do modelo liberal e neoliberal, com a valorização da educação como produto mercadológico, meritocracia, avaliações externas de resultados, centralização do poder, etc.

Não obstante, se no nível do concebido se evidenciam avanços significativos em termos de condições e reconhecimento de direitos dos profissionais da educação, de um modo geral, não há, no plano do vivido, uma efetivação desses discursos. É forte a concepção, inclusive no nível discursivo, de que formação acadêmica e bons salários não surtem, automaticamente, efeito na qualidade de ensino, o que justificaria a necessidade de avaliação de desempenho vinculada aos resultados dos estudantes em exames.

O piso salarial não foi implementado em muitos estados e municípios pela alegação de insuficiência de recursos financeiros ${ }^{5}$. Muitos professores não dispõem de horas de planejamento e formação remuneradas e cumprem uma extenuante jornada de trabalho, atingindo muitas vezes

5 Reportagem da Folha de São Paulo (2011) aponta que 06 redes estaduais brasileiras não cumpriam o valor do piso, em novembro de 2011, entre elas a do Rio Grande do Sul. 
60 horas semanais ${ }^{6}$. Os baixos salários não alcançam investimentos na formação, que em geral fica sob a responsabilidade individual.

Os planos de carreira, quando existentes, não incorporam - ou não implementam - progressão por tempo de serviço ou mérito, nem incentivos à formação. A carreira ainda está longe de ser atrativa, mantendo-se muitas vezes como uma atividade complementar ou sendo assumida por uma parcela da população que não dispõe de condições exigidas para outras carreiras, buscando o exercício do magistério como única e última opção de trabalho.

Não obstante, esse é um cenário em disputa, já que a educação é recolocada no país e em nível internacional como instrumento fundamental do desenvolvimento social e econômico. Muito embora haja, como apresentamos, uma legislação que cobre todo o território nacional, há contextos municipais e regionais muito diversos e desiguais. Nesse sentido, estudos comparativos e estudos de caso são empreendimentos importantes na reflexão, afirmação e propulsão efetivas da valorização docente.

Este estudo do Plano de Carreira de Porto Alegre/RS situa-se no contexto anteriormente exposto. A seguir, serão apresentados os elementos que compõem o plano, contextualizados historicamente no sentido de elucidar sua formulação, cotejando o concebido e o vivido (contemplando questões inclusive que não estão na Lei n. 6.165/88, mas que são direitos adquiridos pelos docentes) bem como relacionando com o acúmulo do movimento nacional disposto na legislação.

\section{O Plano de Carreira de Porto Alegre}

O Plano de Carreira do Magistério Público do município de Porto Alegre foi publicado em 13 de julho de $1988^{7}$, portanto, antes da promulgação da CF/88, em 05 de outubro do mesmo ano. Não obstante, sua formulação está associada ao movimento de redemocratização do país e da valorização das pautas dos movimentos sociais, já que a qualidade da educação para as classes populares era bandeira do candidato eleito nas eleições municipais

6 A citada reportagem da Folha de São Paulo (2011) aponta que 15 redes estaduais descumpriam o limite de 2/3 da jornada com alunos, inclusive o Rio Grande do Sul.

7 Lei n. 6.151/88 (PORTO ALEGRE, 1988a). 
de 1985 em Porto Alegre. Um plano de carreira específico para o magistério, dentre um conjunto de propostas para qualificar a educação, foi um dos compromissos de campanha.

A promessa de campanha eleitoral não se materializou nos primeiros anos de governo. Assim, os professores, organizados e representados através da Associação dos Professores do Município de Porto Alegre (APMPA), na época funcionando como núcleo do Centro de Professores do Estado do Rio Grande do Sul (CPERS), se mobilizaram para tal, concretizando somente no último ano de gestão, pós movimento de greve - 1988 - o encaminhamento da elaboração do Plano de Carreira do Magistério.

O projeto apresentado foi baseado no plano municipal de cargos e salários (Lei n. 5.732/85, revogada por legislações posteriores) e no plano de carreira do magistério estadual, o qual foi discutido com a categoria sofrendo, a partir desse processo, algumas alterações. Muitos dos itens não acordados foram encaminhados para regulamentação posterior, sendo constituída uma comissão com representantes do governo e da categoria com o objetivo de regulamentar o plano através de decreto.

Conforme a entrevista realizada com um membro da comissão representante da categoria à época, muitos avanços e propostas na perspectiva dos trabalhadores foram pactuados na comissão. Porém, a estratégia do governo foi o não encaminhamento do decreto, alegando que estava findando o período da gestão.

O Plano em tela define o Magistério Público Municipal como o conjunto de professores ou especialistas em educação que desempenham atividades docentes ou especializadas, sendo professor aquele integrante do Magistério que possui habilitação específica para atuar em atividades docentes; e especialista em educação aquele com habilitação específica que realiza atividades técnico-administrativo-pedagógicas (PORTO ALEGRE, 1988a).

No título de disposições preliminares, dois cargos anteriores ao plano sofreram rearticulações: 1) o cargo de Professor de Ensino Médio, com seis professores no cargo, com formação técnica, foi enquadrado como cargo em extinção; 2) o cargo de Especialista em Educação não contava 
com nenhum membro, pois nunca houve concurso ou outra forma de contratação. A Secretaria Municipal de Educação (SMED) solicitou aos professores que estavam atuando como supervisores e orientadores nas escolas que declarassem sua opção por continuar no cargo de professor ou por serem alçados ao cargo de Especialista em Educação, já que estariam atuando em desvio de função. Foram conduzidos ao cargo através de ato administrativo e depois desse episódio não houve mais provimento desse cargo.

O Artigo $7^{\circ}$ da Lei remete, para o Anexo I, "a descrição sintética e analítica das atribuições, condições de trabalho, requisitos para recrutamento, ascensão funcional por progressão e promoção e outras características das classes", podendo ser alteradas, conforme parágrafo único do mesmo artigo, através de decreto (PORTO ALEGRE, 1988a). Assim, constam do Anexo I as seguintes atribuições do cargo de professor: orientação da aprendizagem do aluno, participação no processo de planejamento das atividades das unidades de trabalho, organização do processo ensino-aprendizagem e contribuição para o aprimoramento da qualidade de ensino. $\mathrm{O}$ especialista em educação tem a responsabilidade de executar tarefas específicas do planejamento, administração, supervisão escolar e orientação educacional no âmbito da Rede Municipal de Ensino (PORTO ALEGRE, 1988a).

Sobre a distribuição do integrante do magistério, o Artigo $8^{\circ}$ estabelece que ela ocorre por lotação mediante dispositivo estatutário ou por "designação [...] respeitados os direitos adquiridos, podendo ser alterada segundo critérios a serem regulamentados" (PORTO ALEGRE, 1988a). O professor é designado, no momento de sua nomeação, para as escolas em que houver vagas. O recrutamento, a seleção e o ingresso se dão por concurso público, o vínculo empregatício é estatutário e as formas de contratação são: efetivo ou comissão ${ }^{8}$. Esses, como outros itens da carreira, estão dispostos na Lei n. 133/85, que contém o Estatuto dos Funcionários Públicos (PORTO ALEGRE, 1985), e/ou na Lei n.

8 Cargo Efetivo é aquele ao qual é inerente a aprovação em concurso público, nomeação, posse e efetivo exercício, bem como cumprimento e aprovação em estágio probatório para efetivação no cargo, enquanto o Cargo em Comissão é de livre nomeação e exoneração, destinado às funções de confiança, nos cargos de direção, chefia e assessoramento, conforme art. 37, V, CF/88 (BRASIL, 1988). 
6.309/ 88, que dispõe sobre o Plano de Cargos e Salários da administração centralizada (PORTO ALEGRE, 1988b).

A progressão funcional, forma de ascensão funcional dentro da mesma classe e de uma referência para outra imediatamente superior, está prevista nos Artigos 51 e 52 da Lei n. 133/85, na Lei n. 6.165/88 e na Lei n. 6.309/88 sendo regulamentada por decretos. O processo se dá por merecimento e por antiguidade, com critérios que consideram alternadamente princípios de cada modalidade. O Decreto n. 12.091/98 define situações em que o funcionário não terá direito de concorrer em nenhuma das modalidades, ou só por antiguidade, se estiver enquadrado nos afastamentos previstos (PORTO ALEGRE, 1998). Os requisitos para a evolução funcional são publicados através de edital no Diário Oficial de Porto Alegre (DOPA), no qual constam indicadores relacionados à capacitação técnica para o exercício do cargo e à contribuição para o serviço público municipal.

Dentre os indicadores de merecimento, constam escolaridade além da exigida para o cargo, ou curso de pós-graduação afim que não tenha sido utilizado para obter ascensão para o Padrão M5; atuação, como participante ou instrutor, em cursos, seminários, congressos, etc.; participação como membro de inquéritos, comissões e conselhos; premiações de trabalhos e publicações. Na avaliação por antiguidade, são observados os mesmos critérios do funcionalismo em geral, previstos na Lei n. 133/85, na Lei n. 6.309/88 e nos decretos regulamentadores, considerando o tempo de serviço e ressalvadas pontuações negativas por eventuais faltas ou penalidades, previstas no Artigo 11 do Decreto n. 11.091/98.

A periodicidade dos processos é bienal. Para concorrer à progressão, o servidor deve ter, no mínimo, 03 (três) anos de exercício das atribuições próprias do seu cargo na referência em que estiver situado. Além disso, o servidor deve ter, pelo menos, 06 (seis) anos de serviço público para evoluir da referência " $A$ " para “ $B$ "; 12 (doze) anos de “ $B$ " para “ $C$ " e 18 (dezoito) anos de "C" para "D". De 1988 a abril de 2012, a Lei n. 6.151/98 vinculou a progressão ao número de cargos criados na proporção de $40 \%$ na letra A, 30\% na letra B, 20\% na letra C e 10\% na letra D. Assim, 
só se abrem vagas para progressão quando houver menos professores em cada referência do que o percentual de cargos estipulado em lei.

O Plano de Carreira também assegura que ao atingir 30 (trinta) anos de serviço, para os funcionários do sexo masculino, e 25 (vinte e cinco) anos, para os do sexo feminino, sendo ao menos $70 \%$ (setenta por cento) desse tempo dedicados ao município, o profissional tem direito de ascender à referência imediatamente superior à qual estiver situado (PORTO ALEGRE, 1988a). A referida ascensão deve ser solicitada pelo professor através de processo administrativo. Porém, é um recurso que deve ser bem avaliado pelo servidor, já que só pode ser feito uma vez, cessando qualquer possibilidade de progressão por concorrência após esse procedimento. Assim, a menos que o professor já esteja habilitado e decidido a se aposentar, é recomendável que aguarde a possibilidade de progressão pelo processo normal e utilize este como último recurso de progressão antes de encerrar a carreira.

O aperfeiçoamento está previsto no Artigo 21 do Plano de Carreira como "o conjunto de procedimentos que visam proporcionar aos integrantes do magistério a atualização, visando à melhoria da qualidade de ensino" (PORTO ALEGRE, 1988a). É efetivado através de cursos, congressos, seminários, simpósios, palestras, fóruns de debates e outros similares. O Artigo 90 prevê, entre outros itens, o afastamento autorizado sem prejuízo da remuneração, de acordo com o Estatuto dos Funcionários Públicos, em até um terço do regime semanal, desde que o curso seja relacionado ao cargo ou função. (PORTO ALEGRE, 1988a).

No capítulo sobre princípios básicos da carreira, o documento diz que as funções de Magistério são exercidas em diferentes graus - entendidos como as modalidades de $1^{\circ}$ e $2^{\circ}$ graus, quais sejam, currículo por atividades, áreas de estudo e disciplinas e atividades técnico-pedagógicas, desenvolvidas pelos especialistas - de acordo com a formação. A mudança de grau de atuação depende da existência de vagas e deve ser feita conforme regulamento (PORTO ALEGRE, 1988a). Esses itens estão parcialmente desatualizados em relação à LDB de 1996.

A seguir, o Plano de Carreira em tela apresenta, no Artigo 23, quatro princípios básicos, quais sejam: habilitação profissional, condição essencial 
para o exercício da profissão, devendo ser comprovada através de documentação específica; eficiência, que é a "habilidade técnica e relações humanas que evidencie tendência pedagógica, adequação metodológica e capacidade de empatia para o exercício das atribuições do cargo"; consciência social, relativa ao comprometimento "com as transformações sócio-políticas" que envolvem o processo ensino-aprendizagem; e valorização profissional, baseada em condições de trabalho adequadas à “dignidade da profissão e remuneração condigna com a qualificação exigida para o exercício da atividade" (PORTO ALEGRE, 1988a).

O Plano de Pagamento considera o tempo de serviço (em triênios), as já apresentadas referências que estruturam a progressão funcional (A, B, C e D), ambos articulados com os padrões salariais correspondentes à titulação do Magistério, independente do grau de atuação. São esses em número de cinco, definidos no Artigo 24 do Plano de Carreira:

a) M1 - habilitação de Magistério de $2^{\circ} \mathrm{Grau}$, com complementação pedagógica;

b) M2 - habilitação de Magistério de $2^{\circ} \mathrm{Grau}$, com complementação pedagógica mais um ano de estudos adicionais;

c) M3 - habilitação de nível superior em nível de graduação representada por licenciatura de curta duração;

d) M4 - Professor ou Especialista em Educação com habilitação de nível superior em nível de graduação representada por licenciatura plena;

e) M5 - Professor ou Especialista em Educação com Licenciatura Plena complementada por curso de Pós-Graduação em nível de: Especialização com, no mínimo, 360 horas/aula, Mestrado, Doutorado, cumpridas as formalidades da legislação pertinente, desde que haja correlação com a área para a qual tenha sido habilitado em concurso público, ou na qual esteja atuando por remanejo oficial dentro da carreira (PORTO ALEGRE, 1988a).

A proporção/diferença entre os padrões se faz de acordo com os percentuais dos Incentivos, que são formas de atribuir aos profissionais vencimentos de acordo com o padrão correspondente a sua formação: Incentivo I (de M1 para M2) - 15\%; Incentivo II (de M2 para M3) - 35\%; Incentivo III (de M3 para M4) - 55\%; Incentivo IV (de M4 para M5) - 
$82 \%$. Esses percentuais são calculados a partir do vencimento básico correspondente ao Padrão M1.

O profissional tem a possibilidade de ascensão de um padrão para outro superior a qualquer tempo da carreira. Para comprovar a nova habilitação e efetivar a permuta, é exigido certificado de conclusão de curso para o padrão "M2" e diploma para os padrões "M3", "M4" e "M5". O professor faz jus a receber os vencimentos correspondentes ao novo padrão a partir do primeiro dia útil do mês seguinte ao da comprovação (PORTO ALEGRE, 1988a), muito embora o pagamento efetivo possa tardar, conforme informação da Associação dos Trabalhadores em Educação do Município de Porto Alegre (ATEMPA), até dois meses após a entrega dos documentos.

A faixa salarial de cada padrão de habilitação se diferencia e engloba as quatro referências que estruturam a progressão funcional, apresentadas anteriormente, e os adicionais por tempo de serviço, os triênios, que são um acréscimo de cinco por cento (5\%) a cada três anos, sendo que há, aos quinze anos de carreira, um adicional especial de quinze por cento (15\%) e, aos vinte cinco anos de carreira, um adicional de vinte e cinco por cento (25\%), o qual não incide sobre o anterior, mas o absorve.

Dessa forma, por exemplo, um professor que é aprovado em concurso público, tendo formação de nível superior de licenciatura plena, inicia a carreira no padrão M4, na referência " $\mathrm{A}$ ", e vai avançando para as referências $\mathrm{B}, \mathrm{C}$ e D na medida em que se habilita e é aprovado nos processos de progressão funcional. A proporção entre as referências A, B, C e D, conforme o plano, não é inferior a 10\%, se estabelecendo nesse patamar. Junto com esse montante salarial, são acrescentados os valores dos triênios.

O Plano de Pagamento é divulgado anualmente em forma de tabela, constando, na mesma, os Padrões (M1, M2, M3, M4, M5) subdivididos cada um nas Referências (A, B, C e D), publicados também os adicionais por tempo de serviço. Assim, a amplitude atual, no ano de 2011, alcança, considerando todos esses elementos, quatrocentos e trinta e dois pontos percentuais $(432 \%)$.

O padrão salarial dos integrantes do magistério da rede municipal de Porto Alegre é superior ao da rede estadual do Rio Grande do Sul, 
aos de outros municípios e ao próprio piso nacional, já que, a partir de maio de 2011, o salário inicial para o Padrão M1A, ou seja, professor com formação de ensino médio, vinte horas semanais, é de $\mathrm{R} \$ 1.029,60$, alcançando, ao final da carreira, Padrão M5D, R\$4.478,58. A lei do piso salarial, segundo cálculo do Ministério da Educação, estabelece que todos os professores da rede pública de ensino, com formação de nível médio, devem ter piso salarial de $\mathrm{R} \$ 1.187,08$ no ano de 2011 e carga horária máxima de 40 horas semanais. Portanto, o salário inicial em 20 horas semanais, em Porto Alegre, quase alcança o valor do piso nacional para 40 horas semanais de trabalho.

Esse padrão de salário foi construído a partir de alguns acontecimentos peculiares na conjuntura municipal que envolveu o funcionalismo público, já que os salários, em 1988, não estavam nesse patamar, ao contrário, se apresentavam defasados em relação a outras categorias: um aumento em torno de $100 \%$ e política de reajuste salarial bimestral, ambos decretados ao final do governo, em 1988, e assumido pelo governo posterior, que tomou posse em janeiro de 1989. A política de reajuste bimestral vigorou formalmente até 2004, porém desde maio de 2003 os reajustes bimestrais foram suspensos. A política salarial é única para todos os servidores municipais, representados por um único sindicato.

A jornada de trabalho do integrante do Magistério Público de Porto Alegre é de 20 (vinte) horas semanais para os que trabalham nos turnos da manhã ou da tarde e de 18 (dezoito) horas semanais para os que trabalham à noite (PORTO ALEGRE, 1988a). Conforme prevê o Artigo 30, quando convocado, o profissional da educação poderá cumprir regime especial de trabalho, em caráter suplementar ou complementar, correspondendo a um total de 30 (trinta) horas e 40 (quarenta) horas, respectivamente. Nesses dois casos, o profissional fará jus a um adicional em sua remuneração, sendo de $50 \%$ (cinquenta por cento) quando se tratar de regime suplementar e de $100 \%$ (cem por cento) quando se tratar de regime complementar (PORTO ALEGRE, 1988a).

A convocação para regime especial de trabalho deverá ser efetuada através de Portaria do Prefeito mediante proposta fundamentada do titular da Secretaria Municipal de Educação e terá a duração de 2 (dois) anos, 
sendo renovada automaticamente até que o professor ou especialista em educação se manifeste em contrário (PORTO ALEGRE, 1988a).

Um aspecto fundamental que ficou sem regulamentação imediata foi a composição, dentro dessa jornada, de horas de trabalho diretamente com os estudantes, as horas/aula, e as horas destinadas ao planejamento, as horas/atividade. Até 1989, professores das séries iniciais trabalhavam diretamente com os alunos 20 horas semanais, cinco turnos de 4 horas, enquanto os das séries finais trabalhavam 16 horas na escola e dispunham de 4 horas - um turno - para planejamento individual, fora da escola. Portanto, os primeiros não contavam com carga horária de planejamento, o que caracterizava falta de isonomia entre colegas na escola.

A partir de 1989, a gestão que assumiu a SMED decretou 200 dias letivos, estabeleceu 4h30min diárias de atividades com os alunos e determinou uma reunião semanal de 2 horas em todas as escolas, intensificando por um lado a carga horária dos professores dos anos/ séries finais, mas instituindo 2 horas semanais de planejamento na escola, com os estudantes dispensados mais cedo nesse dia. Paulatinamente, as escolas foram supridas com professores de educação física, hora do conto e arte educação, nas primeiras séries/anos iniciais, o que viabilizou horas de planejamento fora da escola para todos, no início quinzenalmente, mais tarde semanalmente.

O Plano de Carreira, no Artigo 38, também garante ao professor a redução do número de horas/aula semanais em função da idade e do tempo de docência. Sendo assim, com 50 (cinquenta) anos de idade e 20 (vinte) de efetivo serviço docente, o educador terá a redução de 2 (duas), 3 (três) ou 5 (cinco) horas/aula para as jornadas de 20 (vinte), 30 (trinta) ou 40 (quarenta) horas semanais, respectivamente. Ao completar 55 (cinquenta e cinco) anos de idade e 25 (vinte e cinco) de docência, a redução será de 4 (quatro), 6 (seis) ou 8 (oito) horas/aula, de acordo com a jornada de trabalho. As horas/aula reduzidas deverão ser compensadas pelo acréscimo de horas/atividade e só ocorrerá mediante solicitação do professor (PORTO ALEGRE, 1988a).

O Plano de Carreira do magistério municipal prevê uma seção sobre atividades especiais, quais sejam, atuação em escolas de difícil acesso e as 
diretamente ligadas ao atendimento de aluno em classe especial. Para o integrante do Magistério Público que trabalha em escola de difícil acesso, é garantido, no Artigo 39, um adicional de $20 \%$ (vinte por cento), calculado sobre o valor básico inicial da classe de professor (PORTO ALEGRE, 1988a). Conforme dispõe o Parágrafo Único do Artigo 34, a "Secretaria Municipal de Educação [publicará], anualmente, a relação das escolas de difícil acesso para fins de concessão da gratificação, baseada nos estudos técnicos realizados pelos órgãos competentes [...]" (PORTO ALEGRE, 1988a).

A outra gratificação, conforme mencionado, se refere ao atendimento de alunos de classe especial. O Inciso II do Artigo 39 prevê que aqueles que realizam atividades diretamente relacionadas com alunos de classe especial, "desde que devidamente habilitados para exercê-las", têm o direito a um adicional de $50 \%$ (cinquenta por cento) nos seus vencimentos - baseados no mesmo cálculo do adicional anterior (PORTO ALEGRE, 1988a).

Essa gratificação contempla atualmente todos os docentes, com ou sem formação específica, que atuam em uma das quatro escolas de ensino fundamental especial, as quais atendem alunos cujas características não permitem a inclusão na escola comum. Portanto, não se exige a formação, por exemplo, dos professores de arte educação, educação física, diretores, supervisores, orientadores educacionais. Igualmente, é garantida para professores que atuam nas Salas de Integração e Recursos que funcionam no atendimento de alunos com necessidades especiais no ensino regular, dos quais se exige formação específica.

Outros adicionais de serviço são conferidos a certas funções, como a de Direção e Vice-Direção Escolar (alçadas através de eleição direta proporcional em cada escola, regida pela Lei municipal n. 7.365/93), Supervisão de Educação, Serviço de Atividades Técnico-Pedagógicas, entre outras. Esses adicionais são previstos no Plano de Carreira (Anexo II) para os denominados Cargos em Comissão ou Funções Gratificadas do Magistério Público Municipal.

Além dos adicionais citados acima, os funcionários públicos de Porto Alegre têm, garantidos em seu Estatuto, o direito à assistência médica, cirúrgica, hospitalar, odontológica e social, estendidas aos seus dependentes. Porém, o atendimento disponibilizado é em um hospital 
sem condições de infraestrutura e equipamentos, com superlotação no atendimento e que não dispõe de todas as especialidades, utilizado em geral pelos funcionários com salários mais baixos.

Ao final de cada ano, é concedida, nos termos do Artigo 98, a gratificação natalina correspondente a 1/12 (um doze avos) por mês de efetivo serviço (PORTO ALEGRE, 1988a). Há ainda uma gratificação especial, no caso de serviço noturno, correspondente a $25 \%$, calculada sobre o valor normal da hora diurna, incidindo sobre as horas trabalhadas no horário compreendido entre $22 \mathrm{~h}$ de um dia e 05horas do dia seguinte. Contempla os professores que atuam em duas escolas que ofertam ensino médio e trinta e oito que ofertam ensino fundamental na modalidade de jovens e adultos. Por fim, conforme a Emenda Constitucional n. 41/03, os servidores em condições de aposentadoria que optam por seguir na ativa têm o abono permanência correspondente ao valor da contribuição previdenciária (BRASIL, 2003).

Além dos incentivos, os integrantes do Magistério também possuem o direito a licenças, que estão regulamentadas no Estatuto dos Funcionários Públicos. São elas: para tratamento de saúde, por motivo de doença em pessoa da família, para repouso à gestante, para fins de adoção e para concorrer a cargo público eletivo e exercê-lo, para prestação de serviço militar obrigatório, para tratar de interesses particulares, para acompanhar cônjuge, para fins de paternidade e como prêmio. Esta última será adquirida ao final de 5 (cinco) anos de efetivo serviço e terá duração de 3 (três) meses. No caso do magistério, a licença prêmio só é concedida ao final da carreira, imediatamente antes da aposentadoria, salvo casos especiais (PORTO ALEGRE, 1985).

Esse mesmo documento também regulamenta alguns afastamentos de menor duração, sem o prejuízo da retribuição pecuniária do servidor, que são concedidos por motivos de casamento, luto, júri e outros serviços obrigatórios por lei (PORTO ALEGRE, 1985). Já as férias alcançam 30 dias, durante o recesso escolar, sendo que os professores desfrutam também dos dias de recesso que excedem os 30 dias de férias, nos meses de julho e fevereiro, desde que não sejam convocados, devendo cumprir antecipadamente parte desses dias nos sábados de 
trabalho, letivos ou de formação.

Outros direitos e vantagens estabelecidos para os servidores são o auxílio-funeral e creche, o vale-transporte e o vale-alimentação (PORTO ALEGRE, 2005). Há a possibilidade de matricular os filhos de 0 a 6 anos em uma escola municipal infantil destinada aos funcionários públicos municipais; porém, a obtenção de vaga é difícil, já que os critérios de seleção incluem menor salário e os professores estão nas faixas salariais mais altas. $\mathrm{O}$ auxílio-alimentação é pago em pecúnia, no valor unitário de $\mathrm{R} \$ 13,00$ (valor vigente em maio/2012), sendo que os professores com 20 horas semanais recebem 15 vezes esse valor ( $\mathrm{R} \$ 195,00$ mensais), os com 30 horas semanais recebem 20 vezes esse valor ( $R \$ 230,00$ mensais) e os com 40 horas semanais recebem 25 vezes o valor unitário ( $R$ \$325,00 mensais). O vale-transporte destina 50 unidades de passagem para quem comprova o uso de uma linha de ônibus de casa ao local de trabalho e 100 para quem comprova o uso de duas linhas. O funcionário contribui com os percentuais de $2,5 \%$ e $5 \%$ do vencimento básico, respectivamente à quantidade de passagens, disponibilizadas através de cartão de uso exclusivo para esse fim. Os professores que não fazem uso desse benefício podem optar pela passagem escolar, cujo subsídio é de $50 \%$ do valor.

O Plano de Carreira do Magistério Público Municipal completa 24 anos de existência em 2012, passando por poucas alterações no período 9 . Na verdade, a maioria dessas mudanças representou avanços por se tratar de regulamentações que garantiram direitos previstos. A categoria dos professores, bem como os demais servidores municipais têm um grande zelo pelo Plano, já que é emblemático no sentido de conquistas e manutenção de direitos. Foi possível, pela conjuntura histórica específica da cidade de Porto Alegre, resistir à ofensiva dos modelos neoliberais, mantendo o documento no contexto de abertura política e afirmação de direitos, retomado com a Constituição Federal de 1998. Passamos, no próximo segmento, a apresentar propostas de alterações e regulamentações ao Plano, efetivadas e não efetivadas.

9 O Plano de Carreira dos professores da rede estadual do Rio Grande do Sul está em vigor desde 1974 (38 anos em 2012), possibilitando se levantar a hipótese de uma cultura e/ou conjuntura local que resiste às alterações, apesar da legislação nacional ter se modificados substancialmente no período. Para mais informações sobre a situação estadual ver MELLO \& LUCE (2011). 


\section{Alterações e regulamentações propostas desde 1988}

Considera-se relevante mencionar que, não obstante a longevidade da vigência do Plano de Carreira de Porto Alegre, o mesmo já passou por algumas alterações e houve movimentos concretos para que modificações mais substantivas fossem levadas a cabo.

Dentre as alterações realizadas, encontram-se a gratificação de difícil acesso (Art. 39, inciso I da Lei n. 151/88), a qual foi regulamentada através do Decreto n. 9.914/91, que caracteriza cinco critérios de difícil acesso, e a gratificação especial (Art. 39, inciso I da Lei n. 151/88), que originalmente contemplava classes especiais e sofreu alteração pela Lei Municipal n. 7.565/94, a fim de contemplar as escolas especiais.

Nos anos de 2002 e 2003, houve um movimento da ATEMPA (sucessora da APMPA), que agregou os trabalhadores não docentes, para regulamentação de alguns elementos do Plano. Foram propostos sete decretos regulamentadores, dos quais apenas um foi efetivado.

A proposta de Decreto n. 01 trazia a definição e estabelecia a equiparação entre os termos: unidades escolares, unidades de ensino e unidades de trabalho. Já a proposta de Decreto n. 02 se referiu à expressão séries escolares, constante do Artigo $3^{\circ}$, esclarecendo seu caráter facultativo previsto na LDB de 1996, equivalente a outras formas de organização, tais como os ciclos, que é a estrutura implementada em Porto Alegre a partir de 1995. O projeto de Decreto n. 03 referiu-se ao Artigo $8^{\circ}$, parágrafo $2^{\circ}$, buscando garantir que "nas eventuais alterações de designação de local de trabalho dos professores, a categoria deverá ser ouvida em constituintes da educação nas unidades de trabalho". Por seu turno, a proposta de Decreto n. 04 elencou mais três critérios para a gratificação de difícil acesso: unidades escolares situadas em locais sem infraestrutura ou saneamento básico; acesso de difícil trafegabilidade em dias de chuva; periculosidade do meio físico em que está inserida a escola. Quanto ao proposto no Decreto n. 05, definia-se a expressão atividades de ensino, incluindo as atividades de esporte, recreação e lazer. Em relação ao projeto de Decreto n. 06, o mesmo propunha, na contagem do tempo de serviço para fins de redução do número de horas/aula semanais 
em função da idade e do tempo de docência, a consideração do tempo cumprido no âmbito municipal, estadual e federal, nas esferas pública e privada. Nenhuma das propostas citadas anteriormente foi acolhida pelo Poder Executivo municipal e efetivou-se como regulamento. A única proposição aprovada, mesmo que com algumas alterações, foi a constante do projeto de Decreto n. 07, o qual formalizou as horas de planejamento, garantidas na prática em todas as escolas de ensino fundamental e médio desde 1998. A discussão ocorrida entre executivo municipal e categoria se referiu ao tempo destinado a essas atividades, as quais constavam no projeto da ATEMPA com 50 minutos, enquanto o governo exigiu hora relógio, ou seja, 60 minutos. O projeto final registrou 50 minutos para as horas/aula e 60 minutos para as horas/atividade.

Porém, ficaram em condição desfavorável, inclusive aquém do estabelecido na Lei do Piso, os professores que atuam em escolas de educação infantil, as quais atendem em tempo integral de 12 horas diárias e contam com monitores e estagiários, além dos professores, para o atendimento. Os docentes, juntamente com os demais trabalhadores da educação infantil, dispõem de dez dias de formação anual, contabilizando 4 horas relógio mensais para uma jornada de 20 horas semanais, mais 6 dias ( 3 no início e 3 ao final) de planejamento no ano. Assim, as jornadas de trabalho possuem a seguinte composição: na jornada de 20 (vinte) horas semanais, 7h e 30min de hora/atividade; na jornada de 30 (trinta) horas semanais; $11 \mathrm{~h}$ e $20 \mathrm{~min}$ de hora/atividade; na jornada de 40 (quarenta) horas semanais, 15h de hora/atividade (PORTO ALEGRE, 2004).

Em abril de 2012, no bojo de alterações no plano de carreira geral, foram alterados também os Artigos 19 e 20 da Lei n. 6.151/88, sendo instituídas mais duas referências na progressão funcional, através das letras E e F, que se por um lado trazem mais mobilidade ao processo, por outro são um convite a permanecer mais tempo na carreira (seis anos para cada nova referência) e desistir da aposentadoria especial. Também foi modificada a lógica do estabelecimento de vagas, antes pelos cargos criados, a partir de então definidas pelo percentual de 30\% dos concorrentes, modificações essas que, pela complexidade das mudanças, não se pode afirmar que se convertam em avanços para a categoria. 


\section{Considerações sobre o plano de Porto Alegre a partir do ordenamento legal pós 1988}

A análise do caso de Porto Alegre nos permite concluir por uma aproximação bastante significativa entre os elementos nacionalmente elencados como indicadores de valorização docente nas diferentes legislações e o exposto no Plano de Carreira do Magistério Público Municipal. Vejamos.

O ingresso é feito mediante concurso público, aferindo os conhecimentos pertinentes ao cargo e área de atuação. Muito embora esteja previsto o ensino médio como formação mínima para a atuação nos anos iniciais, são poucos os ingressantes com ensino médio, já que, pelos atrativos da carreira, há um número relativamente grande de concorrentes em todos os concursos já realizados, inclusive de professores com larga experiência e atuação no nível superior.

Em termos de horário de planejamento e formação, o regulamentado supera o previsto na legislação nacional, atingindo 7h30 min., o que alcança mais de $35 \%$ da carga horária, sendo que 2 horas são individuais e as demais na escola. Além disso, estão previstos 10 turnos de formação, parte planejada pela escola, parte por escolha do professor, outra parte de responsabilidade da SMED. Os professores ainda podem contar com um turno semanal para cursar a graduação ou pós-graduação, desde que tenha relação com o cargo e função. Não estão contemplados, na mesma medida das horas-atividade, os professores que atuam em escolas de educação infantil, que dispõem de 4 horas mensais, muito aquém do previsto, se constituindo em matéria que demanda avanço significativo.

Sobre a carreira, há muitos mecanismos atrativos: progressão funcional que valoriza: a formação acadêmica, a formação continuada e o tempo de serviço, que por um lado é fator que agrega valores ao salário e por outro fator de diminuição das horas-aula. Há incentivo financeiro para que os professores busquem aprimoramento em termos de formação e para que permaneçam na rede municipal de ensino. A categoria dispõe também de vantagens como a gratificação de difícil acesso, que contempla uma parcela significativa, dentre outras que contemplam setores menores. 
Esses mecanismos abrangem o recomendado nas legislações.

Essa valorização, consolidada por vários mecanismos, se expressa na formação dos professores. Conforme dados divulgados pela SMED à ATEMPA, há poucos que ingressaram e se mantiveram com ensino médio, num percentual insignificante. Portanto, a quase totalidade tem curso superior, $70 \%$ já cursou pós-graduação, sendo que desses em torno de $20 \%$ com mestrado e/ ou doutorado. Muito embora a categoria sempre tenha manifestado interesse em ter mais padrões que contemplem a pósgraduação stricto sensu, é uma discussão a ser feita, com prós e contras, para que uma eventual alteração do Plano garanta avanços, e não só um reescalonamento do salário atual.

No que diz respeito aos salários, no comparativo com outras redes de ensino em nível regional e com o previsto no piso nacional, o padrão salarial é relativamente bom. Muito embora já tenha sido historicamente melhor, o movimento organizado dos municipários tem conseguido, através dos processos de data-base que exigiram inclusive a radicalização das estratégias, por meio de greves, manter um nível razoável e recuperar algumas perdas. Portanto, ainda se mantém como um salário atrativo, que pode ser incrementado pela progressão e pelo tempo de serviço.

O objetivo deste artigo foi o de fazer um apanhado geral das concepções e mecanismos da valorização docente presentes no novo ordenamento legal da educação nacional pós 1988, elegendo um caso a ser analisado brevemente, qual seja, o Plano de Carreira do Magistério Público Municipal de Porto Alegre. Não pretendíamos uma análise exaustiva que esgotasse todos os elementos, mas destacar os indicadores mais significativos, na perspectiva de engrossar uma análise crítica que contribua na afirmação da necessidade e possibilidade da valorização docente enquadrada no contexto da afirmação dos direitos e do protagonismo dos trabalhadores em educação na garantia de uma qualidade social da educação, voltada para a relevância e emancipação humanas, através desse interessante objeto de análise, que nos pareceu um exemplo significativo nesse sentido. 


\section{Referências}

BRASIL Constituição (1988). Constituição da República Federativa do Brasil, 1988. Disponível em: <http://www.planalto.gov.br/ccivil_03/ constituicao/ constitui\%C3\%A7ao.htm>. Acesso em: 29 nov. 2010.

. Congresso Nacional. Lei n. 9.394 de 20 de dezembro de 1996. Fixa as Diretrizes e Bases da Educação Nacional. Disponível em: <http://www.planalto.gov.br/ccivil_03/Leis/L9394. htm>. Acesso em: 29 nov. 2010.

. Congresso Nacional. Lei n. 10.172 de 09 de janeiro de 2001. Aprova o Plano Nacional de Educação e dá outras providências. Disponível em: <http://www.planalto.gov.br/ccivil_03/Leis/ LEIS_2001/L10172.htm>. Acesso em: 29 nov. 2010.

Congresso Nacional. Emenda Constitucional n. 41 de 19 de dezembro de 2003. Modifica os arts. 37, 40, 42, 48, 96, 149 e 201 da Constituição Federal, revoga o inciso IX do § 3 do art. 142 da Constituição Federal e dispositivos da Emenda Constitucional n ${ }^{\circ} 20$, de 15 de dezembro de 1998, e dá outras providências. Disponível em: <http://www.planalto.gov.br/ccivil_03/Constituicao/Emendas/ Emc/emc41.htm>. Acesso em: 29 nov. 2010.

. Decreto n. 6.094 de 24 de abril de 2007a. Dispõe sobre a implementação do Plano de Metas Compromisso Todos pela Educação, pela União Federal, em regime de colaboração com municípios, Distrito Federal e Estados, e a participação das famílias e da comunidade, mediante programas e ações de assistência técnica e financeira, visando a mobilização social pela melhoria da qualidade da educação básica. Disponível em: <http://www.planalto.gov.br/ccivil_03/_ato20072010/2007/decreto/d6094.htm>. Acesso em: 29 nov. 2010.

. Congresso Nacional. Lei n. 11.494 de 20 de julho de 2007b. Regulamenta o Fundo de Manutenção e Desenvolvimento da Educação 
Básica e de Valorização dos Profissionais da Educação - FUNDEB, de que trata o art. 60 do Ato das Disposições Constitucionais Transitórias; altera a Lei no 10.195, de 14 de fevereiro de 2001; revoga dispositivos das Leis nos 9.424, de 24 de dezembro de 1996, 10.880, de 9 de junho de 2004, e 10.845, de 5 de março de 2004; e dá outras providências. Disponível em: < http://www.planalto.gov.br/ccivil_03/_ato20072010/2007/Lei/L11494.htm>. Acesso em: 29 nov. 2010.

Congresso Nacional. Lei n. 11.738 de 16 de julho de 2008. Regulamenta a alínea " $\mathrm{e}$ " do inciso III do caput do art. 60 do Ato das Disposições Constitucionais Transitórias, para instituir o piso salarial profissional nacional para os profissionais do magistério público da educação básica. Disponível em: <http:/ / www.planalto.gov.br/ ccivil_03/_Ato2007-2010/2008/Lei/L11738.htm>. Acesso em: 29 nov. 2010.

Conselho Nacional de Educação. Câmara da Educação Básica. Resolução n. 02 de 28 de maio de 2009. Fixa as Diretrizes Nacionais para os Planos de Carreira e Remuneração dos Profissionais do Magistério da Educação Básica Pública, em conformidade com o artigo $6^{\circ}$ da Lei $\mathrm{n}^{\mathrm{o}} 11.738$, de 16 de julho de 2008, e com base nos artigos 206 e 211 da Constituição Federal, nos artigos $8^{\circ}, \S 1^{\circ}$, e 67 da Lei no 9.394, de 20 de dezembro de 1996, e no artigo 40 da Lei no 11.494, de 20 de junho de 2007. Disponível em: <http:/ / portal.mec.gov.br/dmdocuments/ resolucao_cne_ceb002_2009.pdf>. Acesso em: 29 nov. 2010.

Ministério da Educação. In: CONFERÊNCIA NACIONAL DE EDUCAÇÃO, 2010, Brasília. Documento Final. Comissão Organizadora Nacional da CONAE, Brasília, 2010a. Disponível em: <http:/ / conae. mec.gov.br/images/stories/pdf/pdf/documetos/documento_final_ sl.pdf>. Acesso em: 29 nov. 2010.

Congresso Nacional. Projeto de Lei n. 8.035 de 03 de novembro de 2010b. Aprova o Plano Nacional de Educação para o decênio 20112020 e dá outras providências. Disponível em: < http:/ / www.camara. 
gov.br/proposicoesWeb/prop_mostrarintegra?codteor=831421\&filen ame $=$ PL+8035/2010>. Acesso em: 15 mar. 2011.

CAMARGO, Rubens Barbosa de.; JACOMINI, Márcia. Carreira e salário do pessoal docente da educação básica: algumas demarcações legais. Educação em Foco, Belo Horizonte, Ano 14, n. 17, p. 129-167, julho 2011.

GIL, Juca. NETTO, Franciele Nepomuceno. O Plano de Carreira do Magistério em Porto Alegre: abordagens iniciais. In. PERONI, Vera Maria Vidal. ROSSI, Alexandre José. (orgs.). Políticas educacionais em tempos de redefinições no papel do Estado: implicações para a democratização da educação. Porto Alegre: Programa de Pós-Graduação em Educação da UFRGS, Gráfica e Editora UFPEL, 2011, pp.231-246.

MELLO, Elena Maria Billig; LUCE, Maria Beatriz. Gestão do magistério no Rio Grande do Sul (1995-2006): uma análise das políticas de valorização na rede estadual. In: XXV SIMPÓSIO BRASILEIRO POLÍTICA E ADMINISTRAÇÃO DA EDUCAÇÃO, 2011.

NETTO, Franciele Nepomuceno. A (Des)Valorização do Magistério: os casos de Cachoeirinha e de Porto Alegre. 2010. 43 f. Trabalho de Conclusão de Curso (Graduação em Pedagogia) - Universidade Federal do Rio Grande do Sul, Faculdade de Educação, Porto Alegre.

PORTO ALEGRE. Lei Complementar n. 133 de 31 de dezembro de 1985. Estabelece o Estatuto dos Funcionários Públicos do Município de Porto Alegre. Disponível em: <http:/ / www.portoalegre.rs.gov.br>. Acesso em: 29 nov. 2010. . Lei n. 6.151 de 13 de julho de 1988a. Estabelece o Plano de Carreira do Magistério Público Municipal; dispõe sobre o respectivo Plano de Pagamento e dá outras providências. Disponível em: 
<http:/ / www.portoalegre.rs.gov.br>. Acesso em: 29 nov. 2010.

. Lei n. 6.309 de 28 de dezembro de 1988b. Estabelece o Plano de Carreira dos Funcionários da Administração Centralizada do Município; dispõe sobre o Plano de Pagamento e dá outras providências. Disponível em: <http:/ / www2.portoalegre.rs.gov.br.>. Acesso em: 29 nov. 2010.

. Decreto n. 12. 091 de 14 de setembro de 1998. Aprova o Regulamento da Progressão Funcional e dá outras providências. Disponível em: <http:/ / www. portoalegre.rs.gov.br>. Acesso em: 29 nov. 2010.

. Decreto n. 14.521 de 01 de abril de 2004. Regulamenta a disposição constante do art. 29 da Lei n ${ }^{\circ}$ 6.151/88. Disponível em: <http:/ / www. portoalegre.rs.gov.br>. Acesso em: 29 nov. 2010.

. Secretaria Municipal de Administração. Encarte Progressão Funcional: biênio 29/12/2006 a 28/12/2008 - orientações ao funcionário. Porto Alegre: [s.n.], s/d.

. Manual do Servidor Público Municipal: Prefeitura Municipal de Porto Alegre. 2005. Disponível em: <http:/ / lproweb.procempa. com.br/pmpa/prefpoa/sma>. Acesso em: 20 out. 2010.

SAVIANI, Dermeval. O Plano de Desenvolvimento da Educação: análise do projeto do MEC. Educação \& Sociedade, São Paulo, v. 28, n.100, p.1231-1255, ou. 2007.

TAKAHASHI, Fábio; BANDEIRA, Luiza. Estados não cumprem lei do piso nacional para professor. Folha de São Paulo, São Paulo, 16 nov. 2011. Disponível em: <http:/ / www1.folha.uol.com.br/ saber/1007195-estados-nao-cumprem-lei-do-piso-nacional-paraprofessor.shtml>. Acesso em 16 nov. 2011. 


\title{
The teachers career plan in Porto Alegre: reflections from the national legal system after 1988
}

\begin{abstract}
This article intends to contribute to the reflection on the inherent movements and dilemmas in the construction of labor rights of Brazilian teachers by the analysis of the process that defined the contents and practices of Teachers Career Plan in Porto Alegre, Rio Grande do Sul. The main concern was to understand the details of local legislation with regards to the teachers activities, which includes peculiarities such as an $50 \%$ additional in the salary of professionals who work in special education or the reduction of the number of classroom hours per week depending on the teachers age and time of teaching. It was noted that in the analyzed case the intervention performed by trade union organization had strong effect of the acquisition, maintenance and execution of working conditions.
\end{abstract}

Keywords: teachers career plan, labor rights, local education

Recebido: 18/01/2012

Aprovado: 13/06/2012 